\title{
Project-Driving Teaching Research of PLC Integrating Multi-Courses
}

\author{
Li-xin Tian \\ Department of Information Engineering, Tangshan College, Tangshan City, Hebei Province \\ Chinayupoosilon@163.com
}

\begin{abstract}
The course PLC has the characteristics of strong applicability and practicality. Currently, in the course of teaching it exits many shortcomings such as the single teaching form, having less intuitive and vivid, contacting with the other professional courses not closely and so on. Based on this, the paper proposes a project-driving teaching method using the multimedia technology integrating with much knowledge of the professional courses. The teaching method can melt the boring theory learning to the specific project to enrich teaching content, enhance students' learning interest and improve the comprehensive application ability of specialized knowledge of students.
\end{abstract}

Index Terms - PLC, the project-driving teaching, integration of multi professional courses

\section{Introduction}

The Programmable Logical Controller (PLC) is widely used in modern industrial control, such as the control of many kinds of production lines, machine tools, etc. It is one of the main means of realizing industrial automation. At present, the "Programmable Logical Controller" is an important professional course in the domain of the specialty of electrical engineering and automatization or other relative majors. The knowledge of the course involved is wide, the updated development is fast, and it has the closed integration with the actual production and engineering application. So, the course has the comprehensive and practical characteristics.

At present, due to the limitation of hardware resources in the domestic colleges and universities, the present teaching conditions are poorer, so the teachers usually uses the traditional teaching method which mainly depending on the teachers' explanation. The course content is starting from the basic knowledge of PLC including the hardware structure and the instruction system and then the programming method of PLC and the PLC control system design method are introduced in the successive courses. The teaching form and means are single and simple. In the teaching process the engineering examples of the professional field which combined with are less, so that the traditional teaching is boring, especially in the interpretation of the basic instruction and programming method, and students feel abstract and hard to understand. The students' learning interest is not high so it will lead to poor teaching effects.

If apply the interpretation of basic instructions and program design methods to the relevant professional project instances, it can let the students grasp the application of instructions and methods of programming in the practical situations, and make the boring theory unify with the practice together which can improve students' learning enthusiasm. It is conducive to students not only the understanding and mastering of knowledge, but also to develop the students' ability of engineering project design.

\section{Projects Design for Teaching}

Project-driving teaching method makes the projects as the main line and gives the specific control tasks. Guiding by teachers gradually, the implementation plan is designed by the students and finally the students complete the selection of components, the PLC I/O allocation, hardware wiring diagram design and the software programming and debugging. Through the teaching process students can understand PLC instructions and its application step by step under the background of practical engineering, grasp the PLC control system design method, and through the analysis and solving of the problems in the debugging process it can improve the ability of students to find and solve problems so as to improve students' ability in engineering practice.

The key of the project teaching method is to choose and design projects appropriately. The designed projects not only conform to the professional domain, dissolve the corresponding theory knowledge effectively, but also can comprehend knowledge of courses in the specialty. It makes students fully digest the learned-knowledge combining with the contents of professional courses systematically, and narrows the gap between the teaching and practice.

\section{A. Design of Basic Projects}

Based on the teaching contents and teaching requirements of the curriculum, combining with the current social demands for PLC application in industry field, the author designed the projects for teaching which contained the common technology of PLC in industrial control. The designed projects include two categories: the basic projects and the advanced projects. The design of the basic projects is shown in Fig. 1.

The design of projects follows the principle from simple to complex and progressive transformation to integrate the theoretical knowledge and practical operation into together. Through the project-driving teaching process, it makes the students master the basic concepts of PLC, the principle of PLC programming instructions, programming methods, and

This research is supported by the Key Laboratory Project of Tangshan College ( Program No.140080312 ). 
the understanding of the relevant industry control process.

Project one "the free round-trip motion control of the workbench" is the basic for the PLC study, which implements the positive and negative rotation control of the motor which driving the workbench by PLC instead of relay control which studied in the course of "the electric control" and master PLC hardware wiring and basic I/O instructions including contact and coil programming. By project two "intersection traffic lights control", the students mainly learn the programming method of timer instruction. The project can make students understand the working principle of the timer instruction, master the application especially the typical programming of flicker circuit and grasp how to implement cycle control, namely, how to implement the reset to start again of the used timers. Project three "control of production line for packing" mainly train students to grasp the programming and application of counter instructions. Project four, through the control of the liquid mixing device makes the students master the drawing method of sequential function chart and how to transform it into the ladder diagram, understand the difference between the switch and the button as the converting conditions. By project five "control of the cargo vehicle" it can enable students to master the programming method for several working ways and the use of shift instruction. Project six is "control of mechanical arm" which also needs to realize the manual and automatic control. By the project students can study the mixing programming way with experimental method and sequential control method. The difficulty is how to realize the conversion of the step by step mode, single cycle mode and the circular manner which under the automatic way. Project seven is "PID control for analog signals", using the analog input and output terminals, through internal PID instructions and programming to realize the PID control function for temperature. The project fuses the knowledge of the course "detection technology", "the principle of automatic control" and "the process control" together. Project eight is the control of constant-pressure water supply, through which to master how to use PLC to control the frequency converter for motor speed regulation that combines knowledge of "the detection technology", "frequency conversion technology", "electric machinery" and other courses. Project nine "control of fourlayer elevator" can train students' ability of programming and debugging for a system with complex logical relations, and further strengthen the understanding of the application of PLC to realize motor speed control.

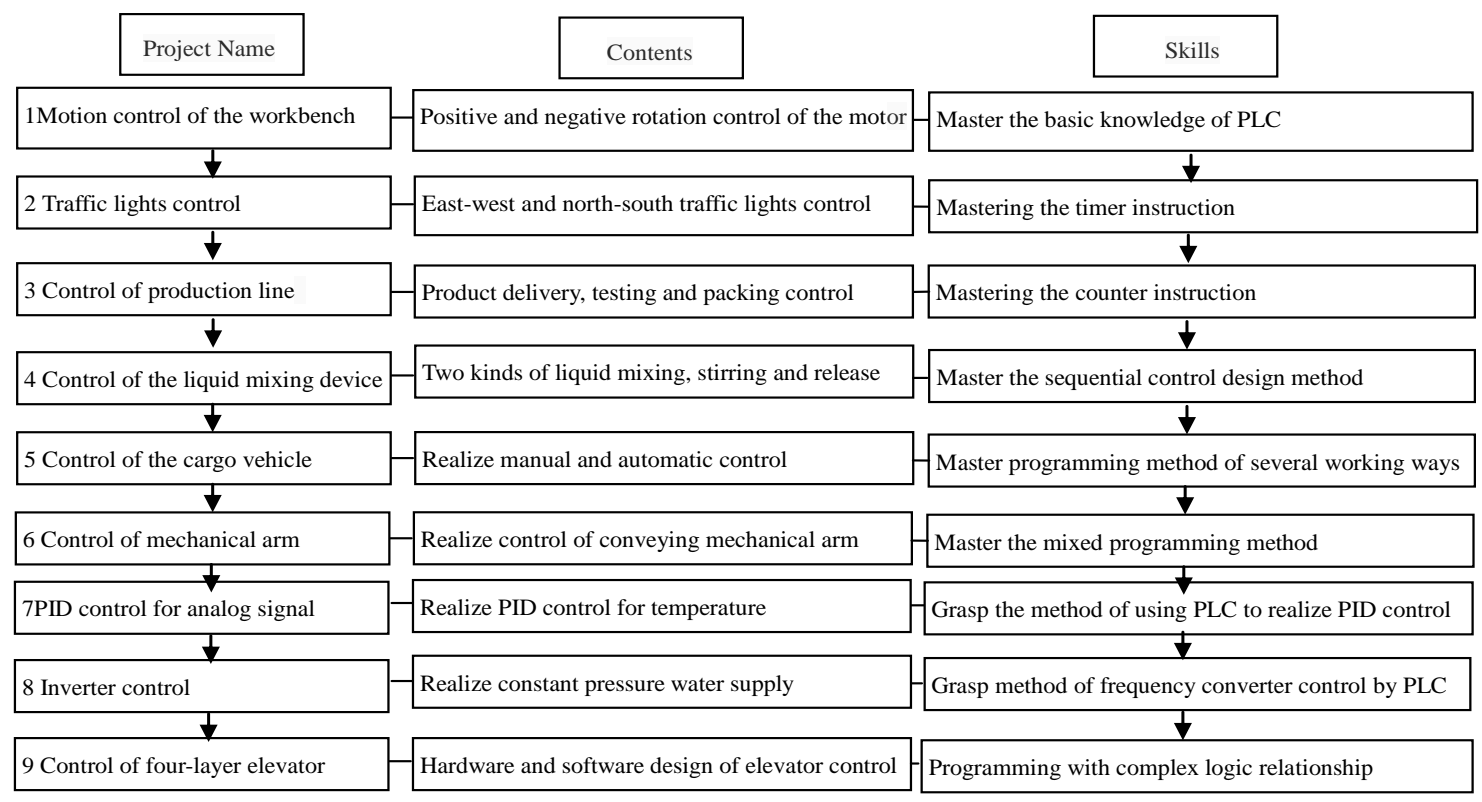

Fig. 1 Basic projects design

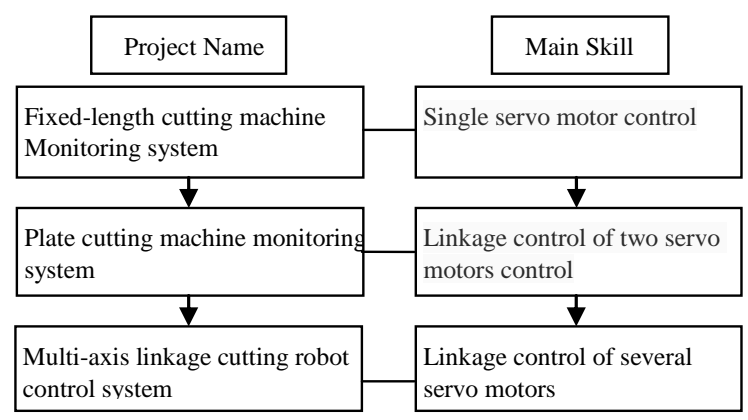

Fig. 2 Advanced projects design 


\section{B. Design of Advanced Projects}

Through the above nine basic projects, students can not only grasp the PLC theoretical knowledge, but also can be familiar with the design process of PLC control systems so as to make the learned knowledge constitute a complete system. On this basis, reviewing in the current industry that machine tool and robot control with PLC as the controller is the one of current mainstream, the author also designed three advanced projects "the fixed-length cutting machine monitoring system", " the plate cutting machine monitoring system" and " the multi-axis linkage cutting robot control system'. They are three comprehensive projects. "The fixed-length cutting machine monitoring and control system" uses PLC as the control center to implement the control of the fixed-length stepper motor and the three-phase AC motor for the band saw. "Flat cutting machine monitoring system" can realize the plane $\mathrm{X}$ and $\mathrm{Y}$ axes linkage control to cut plane figures such as triangles, circles and squares. "Multi-axis linkage cutting robot control system" involves control of servo motors of the Multi-DOF which includes the PC monitoring software development and the design of control program of the lower computer. Because the PLC is lack of PTO outputs, the lower computer makes PLC as the core combinating the positioning control module to achieve the control of multiple servo motors linkage. By the project, students can understand the method using PLC to control more servo motors or stepper motors so as to apply flexibly in other controls such as the control of palletizers, the control of assembly robots and transport robots. The advanced projects design is shown in Fig2.

The three projects are given from simple to complex with the PLC used in servo motor or stepper motor control. It makes the students learn more about the application of PLC in industrial control field especially in motion control. The skills adapt the requirements of the industry development and can supply students an employment platform.

\section{Implementation Process of Project Teaching}

Make the project as the carrier to organize teaching and incorporate the learning process into the project design and implementation. Each project adopts five steps: task analysis, hardware design, programming design, debugging and running. For each project the author made the demonstration courseware with multimedia technology. The teaching completes the five steps adopting the mode of task driving. In the teaching process the tasks are put forward by teachers and the teachers guide students to analyze the workflow and think about the knowledge of the project involved, including the used programming instructions, the logical relationships and the problems of the hardware implementation that need to pay attention to. By task analysis it makes the students clear with the content and target, and then by discussion among teachers and students it can guide the students to complete the hardware design including PLC I/O allocation, drawing electrical schematic diagram, and further the program structure and programming ideas are introduced by the teacher to inspire the students' thinking to complete the whole programming.
Teachers guide students to modify the problems in the programming and debugging process and the project is demonstrated through the combination of configuration software and PLC so that it can enable students to understand intuitively of the whole operation process of the project. This manner can overcome the shortcoming that because of the limited hardware resources for teaching the course content is boring.

\section{A. Implementation of Basic Projects}

The developed basic project management system can run separately from the PLC environment so as to make the students understand intuitively before the control system design, at the same time, the system can run in combination with PLC for program debugging. The project management system frame is shown in Fig. 3.

The configuration picture for the cargo vehicle is as shown in Fig. 4. After the ladder diagram programming is completed, the programmer can input the orders through the configuration picture and can observe the running states of outputs for program debugging.

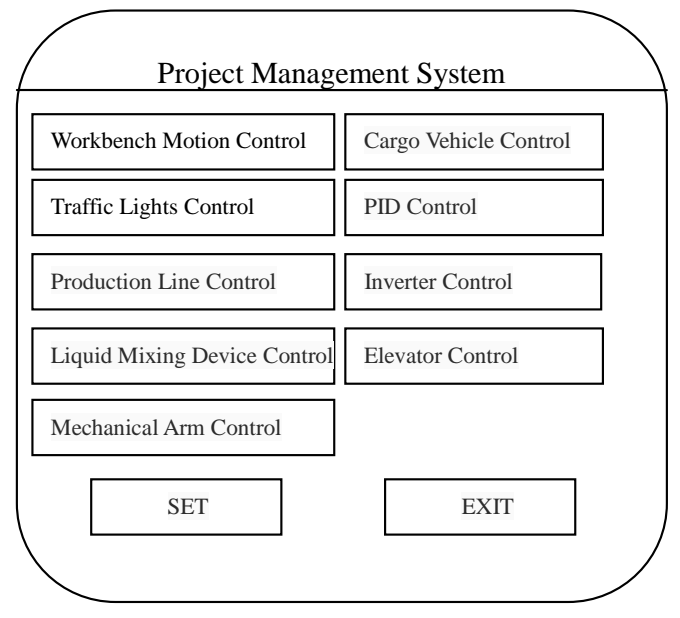

Fig. 3 Project management system frame

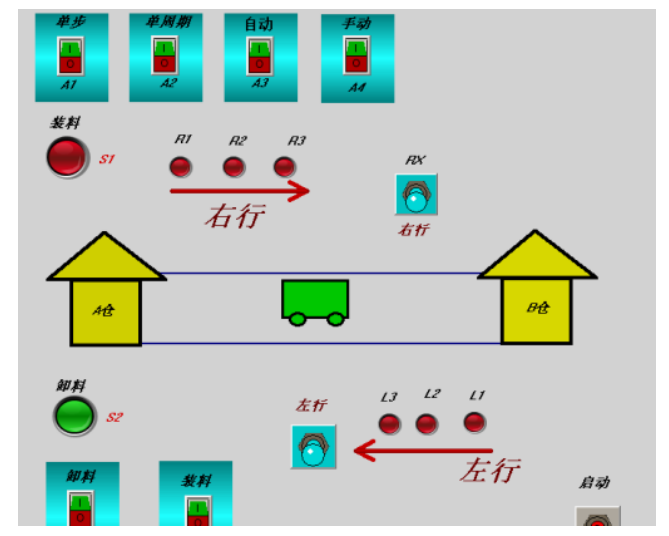

Fig. 4 Configuration picture for the cargo vehicle

\section{B. Implementation of Advanced Projects}

The comprehensive projects "fixed-length cutting machine monitoring system", "flat cutting machine monitoring 
system" and "multi-axis linkage cutting robot control system" require students to design $\mathrm{PC}$ monitor screen according to the learned courses to choose configuration software, LabVIEW, $\mathrm{VC}$, etc., complete the design of the hardware and software according to the control requirements. The three advanced projects also involve more knowledge of courses including servo motor or stepper motor of "electric machinery", encoder of "detection technology", knowledge of inverter and so on. With the project task as the main line, under the guidance of the teacher, students complete the program debugging finally. Through the projects it can really improve the students' ability of comprehensive control system design and practical ability. Fig. 5 is a monitoring surface of the host computer made by the LabVIEW for the fixed-length cutting machine monitoring system. It achieved reading and writing communication with PLC by serial point. By the interface the user can input control commands and parameters of cutting length and it also can reflect the states of the field outputs. The project combines with the curriculum knowledge of the "virtual instrument technology" to achieve the comprehensive application of the studied knowledge.

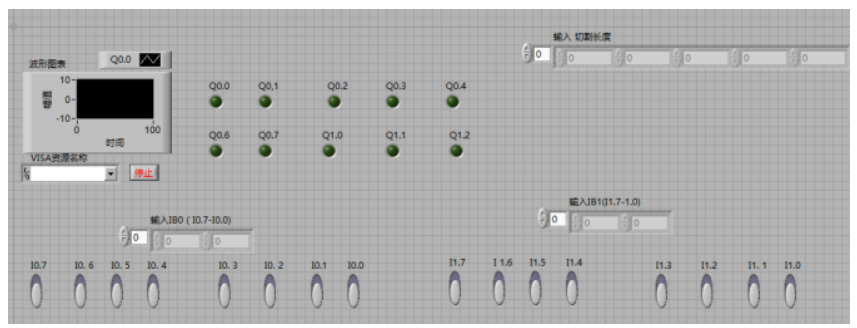

Fig. 5 Configuration screen of fixed-length cutting machine monitoring system by LabVIEW

Fig. 6 and Fig. 7 is the monitoring surfaces of the flat cutting machine control system by KingView. By the interfaces the user can input manual or automatic control commands and observe the parameters of the $\mathrm{X}$-axis and the $\mathrm{Y}$-axis positions. This connected the course "Configuration software" and "PLC" together.

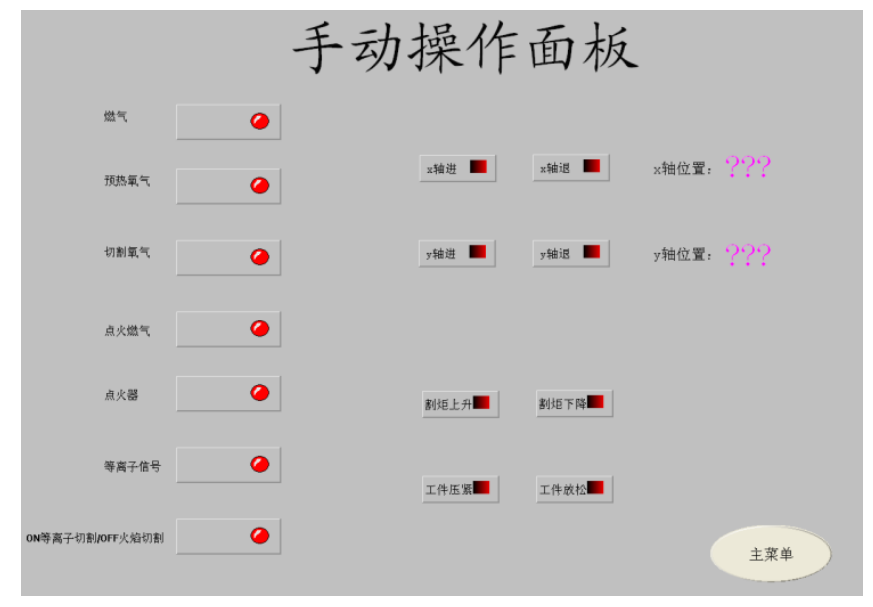

Fig. 6 Manual operation panel of the flat cutting machine monitoring system by KingView

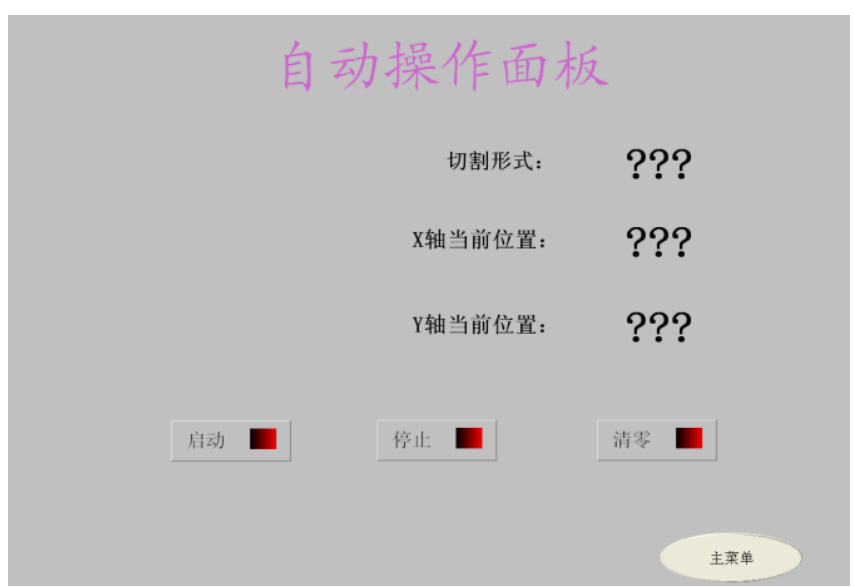

Fig. 7 Automatic operation panel of the flat cutting machine monitoring system by KingView

By this way it can fully mobilize students' autonomy to use knowledge flexiblely so to develop something of value.

\section{Conclusion}

Through the project-driving teaching, the theoretical knowledge can be solubilized in projects from shallow to deep to realize integrating theory with practice. In the process of teaching, the teachers display the teaching contents using multimedia technology in the form of animation to inspire students' thinking. The project-teaching method can greatly improve students' interest in learning, change the students from passive learning to active learning, improve the learning effect and strengthen the degree of students' mastery of knowledge. It broadens the students' eyes by project design which integrated professional courses for field application development. It not only can develop the students' thinking ability and ability of analyzing and solving problems, but also can improve the students' comprehensive skills which lay a foundation for the professional personnel training.

\section{References}

[1] YU Hai-zhen, SHI Xu-hua, LAN Lin-hua, "PLC Experimental Teaching Platform Based on Configuration Technology", JOURNAL OF NINGBO UNIVERSITY ( NSEE ), Vol.23 No.1, pp. 42-45, Jan. 2010.

[2] Chen Dong-hong, "The Design and Implementation Based on the PLC Simulation Training System", University of Electronic Science and Technology of China, 2012.

[3] Wang Rong, "Research and exploration of practical teaching for students majoring in electrical engineering and automation", China Modern Educational Equipment, 2013(19), pp. 64-65,70.

[4] JIANG Jian-fang, LIU Yin, DENG Ming-jian, HUANG Hui. "Design of PLC Experimental System Based on Siemens S7-200", RESEARCH AND EXPLORATIONIN LABORATORY, Vol.27 No.8, pp. 203206,222, Aug.2008

[5] He Li-xin, "Curriculum Reform and Innovation of Programmable Controller Technology Application", China Educational Technology \& Equipment,2010(15):25

[6] Kang Jia-liang, $\mathrm{Xu} \mathrm{Li-jia,} \mathrm{et} \mathrm{al.} \mathrm{"Teaching} \mathrm{reformation} \mathrm{and} \mathrm{practice} \mathrm{in}$ PLC course", Chinese Agriculture Mechanization, 2011,(2): 133-136. 